Revue d'histoire de l'Amérique française

REVUE D'HISTOIRE DE L'AMÉRIQUE FRANÇAISE

\title{
FRANCOIS VEUILLOT - Les Oblats de Marie Immaculée - Collection « Les Grands Ordres Monastiques et Instituts Religieux " - Éditions Bernard Grasset. Un volume in-8, 300 pp.
}

\section{Donat Martineau}

Volume 1, numéro 4, mars 1948

URI : https://id.erudit.org/iderudit/801421ar

DOI : https://doi.org/10.7202/801421ar

Aller au sommaire du numéro

Éditeur(s)

Institut d'histoire de l'Amérique française

ISSN

0035-2357 (imprimé)

1492-1383 (numérique)

Découvrir la revue

Citer ce compte rendu

Martineau, D. (1948). Compte rendu de [FRANCOIS VEUILLOT — Les Oblats de Marie Immaculée - Collection « Les Grands Ordres Monastiques et Instituts

Religieux » - Éditions Bernard Grasset. Un volume in-8, 300 pp.] Revue

d'histoire de l'Amérique française, 1(4), 614-614.

https://doi.org/10.7202/801421ar d'utilisation que vous pouvez consulter en ligne.

https://apropos.erudit.org/fr/usagers/politique-dutilisation/ 
FRANCOIS VEUILLOT - Les Oblats de Marie Immaculee - Collection "Les Grands Ordres Monastiques et Instituts Religieux"-Editions Bernard Grasset. Un volume in-8, 300 pn.

"C'est au Canada, " en 1841, " qu'un petit essaim d'Oblats a préludé à la prodigieuse épopée qui, au témoignage de Pie XI, a placé les fils de Mgr de Mazenod au premier rang des semeurs d'évangile. " Aussi le Canada apostolique a-t-il eu sa large part de mérite et d'honneur dans cette merveilleuse épopée missionnaire qui, des Prairies de l'Ouest canadien et des glaces polaires, passant par l'Afrique Sud, s'est déroulée jusque sous les feux de Ceylan. C'est dire l'intérêt particulier de lógitime fierté avec lequel le lecteur canadien-français accueille cet ouvrage.

L'éminent historiographe nous donne ici une vue d'ensemble des œuvres multiples et variées semées par les Oblats de Marie Immaculée sur tous les continents depuis plus de cent ans. Après avoir évoqué les traits caractéristiques du saint fondateur, son zèle héroĭque pour assurer le renouvellement de l'esprit chrétien en France, spécialement au sein des classes pauvres, l'auteur dégage de la Règle que Mgr de Mazenod a vécue lui-même avant de la léguer à ses fils « la physionomie, le caractère et l'âme de l'Oblat de Marie Immaculée. » Voila le secret de leur apcstolat si fécond déployé en chrétienté et chez les infidèles. Pour décrire cet effort missionnaire vraiment prodigieux, l'auteur a su condenser habilement, en six chapitres de son livre, la substance de plusieurs ouvrages ou de chroniques missionnaires en extrayant de ces sources documentaires les faits essentiels qui marquent les principaux obstacles rencontrés par les missionnaires oblats aussi bien que l'efficacité de leurs communes méthodes d'action civilisatrice.

Tout le livre est animé d'une foi profonde dont l'émotion se traduit en vénération affectueuse pour les héros qu'elle chante et glorifie.

Pour nous, Canadiens, si nous sommes fiers des exploits accomplis par les Oblats en divers pays étrangers, nous ne devons pas perdre de vue que, par leurs sacrifices et leurs labeurs, ils ont les premiers frayé la route à l'évangile et au progrès humain dans les provinces de l'Ouest canadien.

Donat Martindau, prêtre 